\title{
Tradisi Naur Kelaci Dalam Upacara Perkawinan Di Desa Subaya Kecamatan Kintamani, Bangli
}

\author{
I Dewa Gede Adi Pramana ${ }^{1 *}$, I Wayan Suwena ${ }^{2}$, I Gst Putu Sudiarna ${ }^{3}$, \\ Prodi Antropologi Fakultas Ilmu Budaya Unud \\ ${ }^{1}$ [pramanakeroppi@gmail.com], [wsuwena58@yahoo.com], \\ [igpsudiarna@yahooo.co.id] \\ *Corresponding Author
}

\begin{abstract}
Subaya Village is the one of the Desa Bali Aga which is located in Kitamani, Bangli district. This village is still retaining the traditional culture which is given by their ancestors. "Naur Kelaci" is the strict regulation of the marriage for Desa Subaya people. It is held on every purnamaning sasih kasa. The poeple believe on sasihkasa to pay the kelaci, based on their reliance that sasihkasa is the best day in paying the kelaci. Naur Kelaci is the one of the last chain from the wedding ceremony of the people who had been married. Hence, based on the understanding, the problem of this research is stated as the following (1) How is the procces of the NaurKelaci in Desa Subaya? (2) What is the function of Naur Kelaci in the wedding ceremony in Desa Subaya?The proccess of NaurKelaci ceremony could be analyzed by the religious theory, while thefunction, is analyzed by the theory of fuctional structural, and simbolic interaction. NaurKelaci tradition andn wedding ceremony is the concept used in this reserach. This research used ethnography reserach method which is categorized as a qualitative research. In order to get the data, interviewing the participants was conducted. The result of this study shows that the ceremony of Naur Kelaci is purposed to avoid the doom in life especially in the family, and it is the way to purify themselves from the negativety, at once also for the village itself from the dirtiness.
\end{abstract}

Keywords: Tradition of Naur Kelaci, Wedding Ceremony

\begin{abstract}
Abstrak
Desa Subaya merupakan salah satu Desa Bali Aga yang terletak di wilayah Kecamatan Kintamani, Kabupaten Bangli, Bali yang hingga saat ini masih mempertahankan adat dan tradisi yang telah diturunkan oleh leluhur/nenek moyang mereka. Salah satunya tradisi yang mengikat tentang adat perkawinan penduduk Desa Subaya yaitu "Tradisi Naur Kelaci”. Naur Kelaci merupakan salah satu tradisi masyarakat Desa Subaya yang dilaksanakan setiap purnamaning sasih kasa. Dipilihnya sasih kasa sebagai hari pembayaran kelaci dilandasi oleh kepercayaan masyarakat Desa Subaya, bahwa sasih kasa merupakan sasih miik (wangi) hari yang baik untuk membayarkan kelaci. Naur kelaci merupakan salah satu rangkaian terakhir dari proses upacara perkawinan yang diperuntukan bagi warga masyarakatnya yang telah berkeluarga atau yang telah menikah. Adapun rumusan masalah dalam penelitian ini meliputi (1) Bagaimana proses upacara naur kelaci di Desa Subaya(2) Apa fungsi naur kelaci pada upacara perkawinan di Desa Subaya. Proses penyelenggaraanya upacara naur kelaci dapat dikaji melalui teori religi, sedangkan fungsi dari upacara naur kelaci dikaji melalui teori fungsional
\end{abstract}


structural dan interaksi simbolik. Konsep yang digunakan dalam penelitian ini adalah tradisi naur kelaci, dan upacara perkawinan. Penelitian ini menggunakan metode penelitian etnografi yang termasuk kedalam penelitian kualitatif dengan teknik pengumpulan data meliputi observasi partisipasi, wawancara, dan studi kepustakaan. Hasil penelitian menunjukan bahwa upacara naur kelaci yang dilakukan oleh masyarakat Desa Subaya, merupakan salah satu bentuk upacara agar terhindar dari malapetaka dalam kehidupan berumah tangga dan sebagai salah satu bentuk penyucian diri dari sifat-sifat negatif, sekaligus sebagai penyucian desa dari leteh atau (kekotoran).

Kata kunci: Tradisi Naur Kelaci, Upacara Perkawinan

\section{Latar Belakang}

Bali merupakan pulau yang memiliki adat istiadat dan budaya yang begitu cukup beraneka ragam dan bervariasi antara satu daerah dengan daerah yang lainnya, baik dalam tata upacara maupun dalam kehidupan masyarakatnya. Hampir semua masyarakat di seluruh dunia hidup individu dibagi oleh adat masyarakatnya kedalam tingkatan- tingkatan tertentu. Tingkatan- tingkatan sepanjang hidup individu dalam antropologi disebut stages along the lifes-cycle. Hal ini meliputi, : saat masa bayi, masa kanakkanak, masa remaja, masa pubert, masa dimana sudah menikah, masa hamil, masa tua dan meninggal. (Koentjaraningrat, 1967:92).

Saat peralihan yang terpenting pada life cycle dari semua manusia di seluruh dunia adalah saat peralihan dari tingkat hidup remaja ke tingkat hidup berkeluarga. Dalam ajaran Agama Hindu, masyarakat Bali mengenal suatu istilah yang disebut dengan "Catur Asrama" yang merupakan empat tahapan dalam menjalankan kehidupan di dunia. Grahasta merupakan tahapan kedua dalam kehidupan masyarakat Bali yang berarti kehidupan di dalam berumah tangga dengan terselenggaranya prosesi upacara pernikahan atau yang sering disebut dengan "pawiwahan" di Bali.

Begitu pula dengan penyelenggaraan perkawinan di Desa Subaya, naur kelaci menjadi salah satu rangkaian yang harus dilalui setelah melakukan sebuah pernikahan. Naur kelaci merupakan rangkaian akhir dari sebuah pernikahan yang harus dilakukan di Desa Subaya, tujuan dilakukan pembayaran kelaci yaitu untuk membayar hutang semasa hidup, pembersihan diri dari hal-hal yang berbau negatif sekaligus sebagai pembersihan desa dari keletehan (kekotoran).Simbol atau tanda dilihat sebagai konsep- konsep yang dianggap oleh manusia sebagai pengkhasan dan membawa suatu pesan yang mendorong pemikiran atau tindakan yang mencerminkan objeknya dalam hal tertentu (Koenjaraningrat, 2005:291),

Konon pada awalnya masyarakat Desa Subaya saat itu belum sepenuhnya masyarakatnya yang membayarkan kelaci, hanya beberapa dari mereka yang membayarkan kelaci. Lambat laun penduduk Desa Subaya dilanda oleh bencana dan terkena wabah penyakit, warga masayrakat pun merasa resah dengan keadaan tersebut mereka yang terkena bencana dan wabah penyakit setelah dibawa ke pengobatan medis tidak menemukan hasil sama sekali dan pada akhirnya mereka memutuskan untuk ke balean (orang pintar) untuk menanyakan tentang hal tersebut. Yang hasilnya mengatakan bahwa leluhur mereka terdahulu ada yang belum membayarkan kelaci, setelah kelaci tersebut dibayarkan kehidupan penduduk Desa Subya kian membaik.

Semenjak hal tersebut terjadi, kini masyarakat Desa Subaya mulai rutin membayarkan kelaci. Upacara naur 
kelaci dilaksanakan setiap purnamaning sasih kadasa dan purnamaning sasih kasa, kemudian setelah krama desa pekraman Subaya mengadakan paruman atau sangkepan maka pembayaran tersebut disepakati untuk dilaksanakan pada purnamaning sasih kasa. Karena melihat perekonomian masyarakat Desa Subaya yang minim sehingga upacara tersebut hanya dilakukan pada purnamaning sasih kasa dan dalam awigawig tidak diatur untuk keharusan masyarakatnya dalam membayar kelaci, karena kaitanya dengan perekonomian mereka yang minim karna kebayankan dari mereka perekonomiannya bertumpu pada ternak dan ladang yang mereka garp. Menurut keyakinan masyarakat setempat dipilihnya purnamaning sasih kasa karena sasih tersebut merupakan sasih miik ( harum) yang dipercaya sasih yang baik untuk melaksanakan upacara naur kelaci. Kelaci dibayarkan oleh mereka yang telah menikah, baik oleh pihak perempuan maupun pihak laki-laki sama sama membayarkan kelaci Bentuk pembayaran kelaci berupa: $40 \mathrm{Kg}$ babi, 10 butir kelapa, $10 \mathrm{Kg}$ beras, $10 \mathrm{Kg}$ bumbu-bumbu dapur lengkap, 35 lembar daun pisang, dan satu ikat kayu bakar.

Ritual tersebut dilakukan di Pura Puseh Bale Agung Desa Subaya dan nantinya akan dipandu oleh dua orang pemangku, yakni Jero Kubayan Muncuk dan Jero Kubayan Kiwe. Selanjutnya kelaci yang telah dibayarkan oleh kedua pasangan suami istri tersebut akan diracik dan dimasak seperti daging babi dan bumbu - bumbu dapur oleh warga masyaarakt yang hadir dalam upacara tersebut. Setelah usai diracik dan dimasak maka setelah upacara usai akan dibagikan kepada masyarakat setempat. Masyarakat setempat biasa menyebut pembagian tersebut sebagai "kawesan"

Salah satu wujud dari pengaruh ini tampak dalam konsep dan aktifitas yang muncul dalam frekuensi yang tinggi dalam kehidupan masyarakat Bali, baik upacara yang dilaksanakan oleh kelompok kerabat maupun komunitas. Dengan demikian menjadi acuan yang menyebabkan pembayaran kelaci dibebaskan dalam awig-awig, yakni boleh membayar atau tidak, namun karna sampai saat ini masyarakat Bali masih mempercayai dengan adanya hukum karmapala sehingga hal tersebut mereka lakukan. Hal yang membuat penulis perlu melakukan penelitian ini, berdasarkan uraian berikut: disamping Desa Subaya merupakan Desa Bali age yang terdapat di Kintamani, Bangli, karena dengan adanya tradisi seperti ini dapat lebih mengingatkan kepada masyarakat secara umum khususnya masyarakat Bali, bahwa upacara keagamaan harus dilakukan dengan teliti, menurut aturanaturan adat-istiadat keagamaan. Kesalahan kecil sering dianggap dapat membatalkan seluruh magsud dari upacara, bahkan dapat menimbulkan bahaya gaib (Koentjaraningrat, 1967:257).

\section{Pokok Permasalahan}

Berdasarkan latar belakang di atas, maka penelitian ini terfokus pada Upacara Naur Kelaci Dalam Upacara Perkawinan di Desa Subaya Kecamatan Kintamani, Bangli yang selanjutnya dijadikan dua rumusan masalah sebagai berikut:

a. Bagaimana proses naur kelaci pada upacara perkawinan di Desa Subaya?

b. Apa fungsi naur kelaci pada upacara perkawinan di Desa Subaya?

\section{Tujuan Penelitian}

Untuk menjelaskan permasalahan yang akan dibahas dalam penelitian ini dengan rumusan masalah di atas, maka dapat dirumuskan tujuan penelitian sebagai berikut: 1) Untuk mengetahui 
proses awal dari pelaksanaan hingga akhir pelaksanaan upacara naur kelaci di Desa Subaya. 2) Untuk mengetahui fungsi yang terdapat dalam upacara naur kelaci di Desa Subaya.

\section{Metode Penelitian}

Penelitian ini memilih lokasi di Desa Subaya Kecamatan Kintamani, Kabutapten Bangli. Dipilihnya Desa Subaya sebagai tempat untuk melakukan penelitian, dengan alasan bahwa desa ini merupakan salah satu Desa Bali Age yang terdapat di daerah Kintamani. Selain itu dikarnakan salah satu tradisi naur kelaci yang terdapat di Desa Subaya cukup menarik bagi peneliti untuk dijadikan bahan penelitian. Untuk penentuan key informan (informan kunci) ditentukan berdasarkan beberapa kriteria yang dianggap layak untuk dilakukan sebagai berikut: bendesa adat (pimpinan desa adat), Jero Kubayan Kiwe, Jero Bau beberapa tokoh masyarakat lainnya dan warga masyarakat setempat. Jenis data yang digunakan dalam penelitian ini yakni sebagian besar merupakan data kualitatif yang ditunjang dengan data kuantitatif sebagai pendukung.

\section{Hasil dan Pembahasan}

\subsection{Naur Kelaci}

Naur kelaci merupakan salah satu tahapan terakhir yang harus dilewati oleh masyarakat Desa Subaya setelah menikah, naur kelaci dilakukan setiap purnamaning sasih kasa, pada upacara naur kelaci dibayarkan oleh kedua belah pihak yaitu pihak laki-laki dan perempuan. Terdapat dua macam perbedaan dalam konteks pembayarannya yakni jika laki-laki dari Desa Subaya menikahi perempuan yang sama berasal dari Desa Subaya atau dari desa tetangga seperti Desa les, Tejakula, Batih, Siakan, Kutuh, dan Sukawana maka nantinya dalam pembayarannya akan diturunkan terus ke generasi penerus mereka selanjutnya. Sedangkan bagi masyarakat luar yang meminang perempuan di Desa Subaya dan bagi mereka yang dari luar desa selain yang disebutkan tadi memasuki Desa Subaya yang umur pernikahan belum menginjak satu bulan tujuh hari maka penauran kelaci hanya dilakukan sekali saja. Hal ini dianggap oleh masyarakat Desa Subaya bahwa ketika ada orang dari luar desa yang baru menikah dan memasuki Desa Subaya dianggap leteh atau masih kotor sehingga harus dilakukan pembersihan dengan membayar kelaci. Berdasarkan pandangan dalam Agama Hindu bahwa manusia hidup tidak cukup hanya berbuat kebajikan saja tetapi perlu diwujudnyatakan perbuatan tersebut dengan melalui Ritual Agama, oleh karena itu bagi umat Hindu berbuat timbal balik dengan membuat upakara sebagai persembahan kepada sang pencipta (Sudarsana, 2006: 57).

\subsection{Proses Naur Kelaci}

Saat prosesi upacara naur kelaci akan dimulai, tempat yang digunakan dalam proses upacara yaitu di Pura Bale Agung, dalam pelaksanaan upacara naur kelaci nantinya akan disesuaikan dengan fungsi tempat masing-masing yang dibagi menjadi tiga bagian yaitu, nista mandala, madya mandala, dan utama mandala. Dimuali dari nista mandala, nista mandala merupakan areal paling luar dari pura yang merupakan jaba pisan (halaman luar) yang dianggap oleh masyarakat Desa Subaya areal yang tidak suci, sehingga pada halaman tersebut saat upacara naur kelaci digunakan sebagai tempat untuk menimbang babi yang akan digunakan sarana upacara naur kelaci, memerciki air suci kepada babi tersebut, dan penyembelihan kurban babi tersebut.

Selanjutnya memasuki areal halaman tengah, yang disebut dengan madya 
mandala yaitu jaba tengah ( areal tengah pura) yang dianggap oleh masayarakat setempat sebagai tempat berakitifitas keagamaan dan tempat tersebut sudah termasuk areal yang suci. Pada saat upacara naur kelaci tempat tersebut dipergunakan sebagai tempat untuk membuat banten kelaci, penimbangan bumbu-bumbu dapur, perebusan daging babi yang telah disembelih tadi, penyusunan banten kelaci, dan sebagi tempat pembagian kawesan setelah upacara naur kelaci usai dilaksanakan.

Tempat terakhir yang dipergunakan dalam upacara naur kelaci yaitu pada bagian utama mandala ( halaman yang paling dalam dari pura) tempat tersebut merupakan areal yang paling suci dari Pura Bale Agung. Pada saat upacara naur kelaci tempat tersebut dipergunakan sebagai tempat terakhir dalam rangkaian upacara naur kelaci yaitu, untuk tempat matur piuning, tempat menghaturkan sesajen naur kelaci seperti banten urip dan sarana lainnya yang dipersembahkan, dan digunakan untuk tempat persembahyangan oleh para masyarakat yang membayarkan kelaci.

\subsection{Upacara Naur Kelaci Sebagai Peralihan Status Setelah Menikah}

Masyarakat Desa Subaya melakukan upacara naur kelaci ketika seseorang di desanya telah melewati proses perkawinan dan sah menjadi sepasang suami istri atau telah berkeluarga, setelah melewati proses tersebut maka mereka akan dianjurkan untuk melakukan proses atau tahap terakhir yakni naur kelaci. Meski dalam awig-awig di Desa Subaya tidak mengharuskan masyarakatnya untuk harus naurkelaci, namun kepercaayaan masyarakat setempat akan tradisi yang telah diturunkan secara turun - temurun oleh nenek moyang mereka terdahulu hingga kini masih melekat di diri mereka, sehingga sampai saat ini tradisi tersebut masih dilaksanakan.

Upacara pawiwahan (pernikahan) juga tidak bisa terlepas dari desa dresta. Desa dresta merupakan suatu tradisi agama Hindu yang telah menjadi tradisi desa yang berlaku dalam suatu wilayah tertentu, yangmana tradisi tersebut bukan bersumber dari pustaka suci melainkan telah diyakini oleh masyarakat desanya (https://ejournal.ihdn.ac.id) diakses pada 31 januari 2018.

\subsection{Upacara Naur Kelaci Sebagai Penyucian diri dan Penyucian Desa}

Masyarakat Desa Subaya juga meyakini jika upacara tersebut tidak dilaksanakan maka akan menimbulkan kekotoran pada diri orang yang tidak membayar kelaci begitu juga Desa Subaya menjadi "leteh" (kotor). Mereka yang dianggap membuat leteh di Desa Subaya merupakan pendatang dari desa lain yang usai pernikahan mereka belum mencapai satu bulan tujuh hari yang tibatiba memasuki daerah Desa Subaya, maka orang tersebut dikenakan naur kelaci untuk penebus karna telah membuat desa tersebut leteh (kotor). Terkadang masyarakat pendatang yang masuk ke Desa Subaya tidak mengetahui alasan mengapa mereka bisa dikenai denda kelaci, karena tidak adanya pemberitahuan sama sekali dari pihak desa tentang alasan denda tersebut. Namun percaya tidak percaya orang yang melanggar aturan tersebut akan meraskan sendri melalui mimpi-mimpi bawah sadar mereka (secara niskala) ataupun melalui gejala-gejala sakit yang tidak awam atau tidak normal dirasakan dan tidak kunjung sembuh, yang kemudian menyadarkan mereka nantinya untuk membayar kelaci di Desa Subaya. 


\section{Simpulan}

Upacara naur kelaci merupakan sebuah upacara sakral yang dimiliki oleh masyarakat Desa Subaya dan upacara tersebut dilaksanakan oleh masyarakatnya yang telah menikah dan oleh leluhur-leluhur mereka yang telah meninggal namun belum sempat memnbayar kelaci, naur kelaci merupakan rangkaian terakhir dari upacara perkawinan yang harus dilalui, upacara naur kelaci dilakukan atas dasar pengalaman dan pristiwa yang dirasakan oleh leluhur-leluhur mereka terdahulu, yangmana pada saat itu terjadi grubug (malapetaka) karena warga masyarakatnya yang pada saat itu tidak ada yang melakukan upacara naurkelaci sehingga lambat laun barulah tradisi tersebut mulai dilaksanakan kembali agar hal-hal yang tidak diinginkan tidak terulang kembali, dan para warga masyarakat berharap dengan dilaksanakannya upacara naur kelaci kehidupan rumah tangga yang dijalani oleh masing- masing masyarakat Desa Subaya menjadi rukun, begitu juga kehidupan masyarakat Desa Subaya diharapkan tentram dan tidak terjadi lagi hal buruk lainnya yang menimpa warga masyarakatnya.

Disamping hal tersebut, diharapkan pada generasi muda di Desa Subaya bisa menjadikan tradisi naur kelaci sebagai pemblajaran agar tidak melakukan pernikahan secara dini, karena konsekuenis dan tanggung jawab yang sangat besar .

\section{Saran}

Berkaitan dengan hal tersebut maka penulis menyampaikan saran agar mendapat perhatian dari pihak-pihak yang terkait yakni sebagai berikut:

Masyarakat Desa Subaya diharapkan agar dapat melestarikan budaya yang telah diwariskan maupun yang telah dimiliki saat ini, kususnya tradisi naur kelaci agar dikemudian hari dapat diwariskan ke generasi muda Desa Subaya. Sehingga nilai-nilai yang tertuang dalam budaya tersebut dapat tetap tertanam di masing-masing pribadi setiap orang serta nilai-nilai yang terkandung dalam kebudayaan tersebut dapat diterapkan dalam kehidupan bermasyarakat, dan bagi pihak pemerintah agar lebih mengkaji dan mengapresiasi tradisi upacara naur kelaci dalam upaya pelestarian terhadap budaya lokal.

\section{Daftar Pustaka}

Koentjaraningrat,

1967.AntropologiSosial. Jakarta: PT Dian Rakyat

Koentjaraningrat, 2005.Pengantar Antropologi pokok-pokok Etnografi 2. Jakarta: Rineka Cipta

Sudarsana, I.B. Putu. 2006. Ajaran Agama Hindu UPADECA: Yayasan Dharma Acarya.

\section{Sumber Media Online}

https://ejournal.ihdn.ac.id 